\title{
Uma Aplicação do Software Educacional PhET Como Ferramenta Didática no Ensino da Eletricidade
}

\section{An Application of The PhET Educational Software as a Didactic Tool in the Teaching of Electricity}

\section{Resumo:}

Um desafio da educação é fazer um bom uso das tecnologias digitais como ferramenta didática no processo ensino-aprendizagem. Trabalhando com essa problemática, o nosso trabalho tem como objetivo avaliar possibilidades e limitações do Portal Tecnologia Educacional em Física (PhET) nas aulas de Física, investigando melhorias na aprendizagem de conceitos básicos de eletricidade, a luz da teoria da aprendizagem significativa de David Ausubel e do uso das TIC. Assim, aplicamos um questionário para análise do conhecimento prévio dos educandos, quando percebemos que para alguns pontos os alunos possuíam concepções, em sua maioria, de senso-comum, fugindo do conhecimento científico. Após a realização das simulações feitas em sala de aula, percebemos que os alunos modificaram esse conhecimento, sendo comprovado através de uma entrevista no final dessa investigação. De acordo com as observações desta pesquisa, percebemos uma real contribuição do PhET no processo ensino-aprendizagem dos conteúdos que nos propomos trabalhar.

Palavras-Chave: Aprendizagem significativa. TIC. PhET. Eletricidade.

\begin{abstract}
:
An education challenge is to make a good use of digital technologies as a didactic tool in the teaching-learning process. Working with this question, our work aimed to evaluate possibilities and limitations of Portal PhET in physics classes, investigating improvements in the learning of basic concepts of electricity in the light of David Ausubel's theory of the meaningful learning and the use of ICT's. Thus, we applied a questionnaire to analyze the previous knowledge of the students, when we realize that for some points students had most conceptions of common sense, escaping from the scientific knowledge. After the realization of simulations in the classroom, we realize that students have modified that knowledge, being proven through an interview at the end of this investigation. According to the observations of this research, we perceive a real contribution of the PhET in the teaching-learning process of the contents that we propose to work.
\end{abstract}

Keywords: Meaningful learning. ICT. PhET. Electricity.

ARAÚJO, Francisco Vanderli de; NOBRE, Francisco Augusto Silva; ANDRADE JUNIOR, José Adauto; DANTAS, Claudio Rejane da Silva. Uma Aplicação do Software Educacional PhET Como Ferramenta Didática no Ensino da Eletricidade. Informática na Educação: teoria e prática, Porto Alegre, v. 18, n. 2, p. 145-161, jul./dez. 2015.
Francisco Vanderli de Araújo

Francisco Augusto Silva Nobre

José Adauto Andrade Junior

\section{Introdução}

M uito se tem discutido sobre como se ensinar os conteúdos das chamadas ciências exatas, física, especificamente. Em nossa experiência como professores desta área do conhecimento, são comuns os relatos de nossos colegas de profissão sobre as dificuldades em transmitir os conteúdos nessa área, como é comum também, escutarmos de nossos estudantes a afirmação de que a disciplina de física é de difícil compreensão. Isso nos faz pensar em mudar nossa prática em sala de 
aula, para levar o estudante ao que chamamos de aprendizagem.

Nesse trabalho investigamos o aprendizado de educandos do ensino médio, quando utilizamos simulações computacionais de um portal desenvolvido por pesquisadores da Universidade do Colorado (EUA). O PhET ${ }^{1}$ - Tecnologia Educacional em Física, é um Portal que apresenta diversas simulações em várias áreas das ciências, e podem ser usadas on-line ou baixadas gratuitamente. Assim, nessa investigação utilizamos as Tecnologias da Informação e Comunicação (TIC) no intuito de avaliarmos suas vantagens na melhoria do ensino-aprendizagem dos educandos do ensino médio na disciplina de Física, mais exatamente, para o conteúdo de eletricidade.

As TIC entram no espaço escolar mesmo que tenhamos dúvidas quanto à eficácia de seu uso. Entram muitas vezes sem consulta aos professores, sendo necessário então um pensar crítico acerca de suas potencialidades e riscos. Sabemos que as TIC são de grande importância na sociedade em que vivemos, sendo responsáveis diretas do desenvolvimento de novas e modernas tecnologias. É bom entendermos que as tecnologias estão presentes em nossas vidas desde o homem primitivo.

Quando os nossos ancestrais pré-históricos utilizaram-se de galhos, pedras e ossos como ferramentas, dando-Ihe múltiplas finalidades que garantissem a sobrevivência e uma meIhor qualidade de vida, estavam produzindo e criando tecnologias. (KENSKI, 1998, p. 59, grifo do autor)

Constatamos que o Portal PhET disponibiliza uma grande quantidade de simulações simples e interativa, apresentando fenômenos que di- ficilmente seriam vistos a olho nu, ou mesmo, precisariam de um grande aparato técnico. Um ponto positivo deste Portal é a acessibilidade e facilidade para realização das simulações, conforme argumentam:

Um aspecto que merece destaque trata da facilidade de acesso e a possibilidade de rodar a simulação em qualquer equipamento sem a necessidade de recursos altamente específicos. Todas as simulações podem ser usadas diretamente na página principal, mas também é permitido o download. Elas são geralmente desenvolvidas em Flash e, se o computador não tiver o plug-in, o usuário é direcionado a baixar e instalar o recurso na sua máquina de forma simples. (ARANTES; MIRANDA; STUDART, 1996, p. 29)

Utilizaremos como base teórica neste trabaIho, a teoria da Aprendizagem Significativa de David Ausubel. Esta teoria diz que o sujeito assimila um novo conhecimento baseando-se em conhecimentos prévios, onde Ausubel denomina de subsunçores. A partir daí, o educando constrói um novo conhecimento ou reformula o conhecimento prévio existente na sua estrutura cognitiva. Temos:

A aprendizagem por recepção significativa envolve, principalmente, a aquisição de novos significados a partir de material de aprendizagem apresentado. Exige quer um mecanismo de aprendizagem significativa, quer a apresentação de material potencialmente significativo para o aprendiz. (AUSUBEL, 2002, p. 17, grifo do autor)

Partimos do pressuposto que os recursos de simulações do Portal PhET possam se constituir em um material potencialmente significativo para a aprendizagem.

${ }^{1}$ Disponível em: <http://phet.colorado.edu/> Acessado em 13 de fevereiro de 2013. 


\section{Tecnologias da Informação e Co- municação (TIC)}

A sociedade atual é influenciada por inúmeros avanços tecnológico em todos os campos da ciência. Atualmente, direta ou indiretamente, fazemos o uso das TIC, no entanto, devemos sempre utilizar procedimentos e recursos adequados e viáveis para a solução de cada problema do nosso cotidiano.

Este desenvolvimento tecnológico tem modificado profundamente o cotidiano das pessoas, e a escola não pode ficar alheia a essa realidade, ela precisa se adaptar e ensinar ao aluno como conviver com essas novas tecnologias (TIC'S) também dentro da escola, para que ele possa atuar como cidadão participante dentro e fora do contexto educacional. (MELO, 2010, p. 3)

O aluno está inserido na sociedade, e diante disso, é importante e inevitável o uso de tecnologias da informação e comunicação no ambiente escolar, cabendo às escolas e aos professores, transformar essas tecnologias em ferramentas para facilitar o processo ensino-aprendizagem. Um papel da educação escolar neste momento é engajar os alunos no contexto das TIC, tornando-o atuante não somente na sua escola, mas também no meio social onde o mesmo está inserido. O uso das novas tecnologias aplicadas ao ensino de física proporciona uma melhoria no ensino aprendizagem.

Nesta perspectiva, conjecturamos que a relação entre o conteúdo sistematizado da disciplina de Física vista em sala de aula com as novas tecnologias da informação e comunicação, poderia permitir um maior interesse por parte dos alunos, possibilitando uma aprendizagem significativa e motivadora, com o processo de construção do conhecimento sistematizado a partir de seus conhecimentos prévios. (NOBRE; DANTAS; ANDRADE JUNIOR, 2010, p. 22)

Concordamos com MELO (2010, p. 3), quando argumenta que "[...] estudos recentes mostram que a utilização de novas tecnologias no ensino, em geral, e em especifico no ensino da física, tem contribuído de forma significativa para a compreensão por parte dos alunos dos conteúdos físicos [...]". As tecnologias se bem utilizadas podem fazer com que os alunos aprendam a caminhar sozinho: "É através das ferramentas tecnológicas, e a partir de mediações atuantes que as potencialidades se afloram [...]" (SANTOS, 2006 apud MELO, 2010, p. 4).

Devemos enfatizar que, mesmo sendo potencialmente educativo, o uso das tecnologias no ensino devem sempre ser mediadas e acompanhadas pelos professores. O seu mau uso pode desencadear problemas no processo ensino-aprendizagem. Precisamos mudar a nossa forma de ensinar e aprender na nova sociedade do saber, pois percebemos em nossa prática como professores, que o uso das TIC na escola, quando usada de forma planejada pelo professor, pode torna-se uma valorosa ferramenta para uma aprendizagem realmente significativa.

\subsection{O Uso do PhET}

Um dos pontos positivos de utilizar as simulações computacionais é "[...] servir como demonstrações em aulas expositivas. Nesse caso, a principal contribuição consiste em visualizar conceitos abstratos [...]" (ARANTES; MIRANDA; ESTUDART, 2010, p. 29).

Os simuladores computacionais são materiais didáticos denominados objetos de apren- 
dizagem (OA). Temos que "[...] um dos mais disseminados tipos de OA são as simulações computacionais de experimentos de física, que estão disponíveis para utilização em diversos contextos [...]". (ARANTES; MIRANDA; ESTUDART, 2010, p. 27)

Em nosso trabalho exploramos o Portal PhET, pela facilidade de seu uso, por ser gratuito, e por contar com um banco de mais de 90 milhões de possibilidades de simulações (nenhum outro possui tantas simulações). Este, não oferece apenas simulações na área de Física, e podemos encontra-las bem organizadas e distribuídas, facilitando assim a compreensão de quem vai utiliza-las.

Todas as simulações existentes no PhET são bem planejadas, desenvolvidas e avaliadas antes de serem publicadas no Portal. Destacamos também a sua simplicidade na utilização, permitindo que o educando descubra sozinho novas formas de aprender. A maioria dos comandos é ativada ou desfeita com apenas um clic, fazendo com que os educandos utilizem de maneiras variadas as simulações, interagindo e construindo um novo conhecimento no seu cognitivo.

\section{A Teoria da Aprendizagem signifi- cativa}

Neste momento apresentaremos a Teoria da Aprendizagem Significativa. O que diz essa teoria? Por que a mesma foi escolhida para esta investigação? Por fim, qual a sua importância na sociedade do conhecimento?

A Teoria da aprendizagem significativa é uma teoria formulada por David Ausubel, onde este procurou apresentar uma teoria cognitiva de aprendizagem em oposição às teorias verbais utilizadas nas escolas, que fazem o uso excessivo de memorizações. O mesmo defende que a aquisição e retenção dos conhecimentos provêm de ideias relevantes já existentes na estrutura cognitiva do indivíduo e confronta com novas ideias para a formulação de um novo conhecimento.

Para uma compreensão inicial da Teoria da aprendizagem significativa é necessário entendermos que:

O processo de aquisição de informações resulta em uma alteração quer das informações recentemente adquiridas, quer do aspecto especificamente relevante da estrutura cognitiva, à qual estão ligadas as novas informações. Na maioria dos casos, as novas informações estão ligadas a um conceito ou proposição como ideias relevantes da estrutura cognitiva. De forma a indicar que a aprendizagem significativa envolve uma interação seletiva entre o novo material de aprendizagem e as ideias preexistentes na estrutura cognitiva, iremos empregar o termo ancoragem para sugerir a ligação com as ideias preexistentes ao longo do tempo. (AUSUBEL apud DANTAS, 2011, p. 57, grifos do autor)

Aprender é reter e utilizar grandes conjuntos de informações. A maneira com que as informações são passadas para o sujeito da aprendizagem faz com que o mesmo, assimilando essas informações, transforme o conhecimento prévio presente no seu cognitivo, ou formule um novo conhecimento. Este conhecimento prévio, Ausubel denomina de subsunçores,

A linguagem é um importante facilitador da aprendizagem significativa por recepção e pela descoberta. Aumentando-se a manipulação de conceitos e de proposições, através das propriedades representacionais das palavras, e aperfeiçoando compreensões subverbais emergentes na aprendizagem por 
recepção e pela descoberta significativas, clarificam-se tais significados e tornam-se mais precisos e transferíveis. (AUSUBEL, 2002, p. 21)

A disciplina de Física, por muitas vezes, é vista como uma disciplina que exige uma grande memorização de teorias, leis e fórmulas matemáticas, forçando o aluno a uma aprendizagem por memorização. Para Ausubel (2002), a aprendizagem significativa e aprendizagem mecânica estão em um contínuo, sendo dois extremos, mas não são dois opostos. Na aprendizagem por memorização o conhecimento é retido, mas, logo é apagado na estrutura cognitiva do indivíduo. Já na aprendizagem significativa isso não ocorre, pois o sujeito compara o novo conhecimento com o conhecimento já existente (subsunçor), assim o novo conhecimento é reformulado e internalizado.

Sabemos que o educando não é uma folha em branco, todos os alunos já trazem no seu cognitivo um conhecimento prévio, que muitas vezes são identificados como senso comum. A ideia dessa teoria é dar novos significados a esse conhecimento prévio. Segundo Ausubel (2002), os conceitos estão no cognitivo no indivíduo de forma hierárquica, organizados de acordo com a sua complexidade. O novo conhecimento em confronto com o existente irá dar um significado a essa organização. Assim, o objetivo principal dessa investigação é observar a retenção de novos conhecimentos por parte dos educandos, reformulando o conhecimento prévio existente ou formulando um conhecimento novo através do uso de simulações computacionais.

Especificamente, fizemos uso das simulações do Portal PhET e avaliamos o impacto deste no aprendizado dos educandos. De acordo com Moreira (apud DANTAS, 2001, p. 58), as simulações fazem com que haja uma maior interação do aluno com o professor, havendo interação, os conhecimentos se modificam: o novo passa a ter significado para o indivíduo e o prévio adquire novo significado.

Acreditamos que teoria de Ausubel tem uma enorme importância no cenário atual da pesquisa em ensino, e fortemente para a abordagem da física. Geralmente os educandos vêm de uma escola fundamental onde o ensino de ciências é demasiadamente teórico, expositivo, distante da realidade dos alunos e de uma ciência mais atual. Concordamos com ideia de que:

A aprendizagem é muito mais significativa à medida que o novo conteúdo é incorporado às estruturas de conhecimento de um aluno e adquire significado para ele a partir da relação com seu conhecimento prévio. Ao contrário, ela se torna mecânica ou repetitiva, uma vez que se produziu menos essa incorporação e atribuição de significado, e o novo conteúdo passa a ser armazenado isoladamente ou por meio de associações arbitrárias na estrutura cognitiva. (PELLIZARI; KRIEGL, 2002, p. 37)

Dessa forma, entendemos que a teoria da Aprendizagem Significativa de Ausubel nos torna mais ativos no ensinar, mais próximos dos educandos, o que nos leva a pensar em reorganizar o sistema educativo, reformular os currículos e inserir uma nova oferta de conteúdos e metodologias de aprendizagem para as escolas. Em outras palavras, para que a mudança da funcionalidade do sistema educativo seja verdadeira, entendemos ser necessária uma profunda reforma de conteúdos e métodos. 


\section{Metodologia e Caminhos da Pes- quisa}

Percebemos que na maioria das vezes as aulas de física são expostas apenas com a utilização do quadro branco, e com excessiva exposição de fórmulas, causando a fadiga nos estudantes e consequentemente o desinteresse pela área. Considerando esse problema, iremos utilizar o Portal PhET para aplicarmos simulações computacionais na sala de aula, com o pressuposto que esse recurso torne as aulas mais prazerosas e dinâmicas para os educandos, e ao mesmo tempo ajudem para obtenção de uma aprendizagem significativa.

A presente pesquisa é de natureza qualitativa, visto que nosso propósito não foi quantificar a fala dos educandos, e sim ressaltar o modo como eles relatavam o objeto de pesquisa. Para isso, iniciamos a intervenção aplicando um questionário com o objetivo de registramos os conhecimentos prévios dos alunos. E durante todo o processo fizemos um Diário de Campo, onde descrevemos tanto os avanços dos educandos, no que diz respeito aos conhecimentos de eletricidade, como a motivação dos mesmos para aprender o conteúdo em questão, e ainda sua percepção sobre o uso do Portal PhET. Para finalizar, realizamos entrevistas com uma parcela dos estudantes, o que fortaleceu as percepções do Diário de Campo.

As falas dos educandos registradas no Diário de Campo, como também as obtidas nas entrevistas, permitiu-nos observar os avanços dos alunos no que respeito à aprendizagem do conteúdo de eletricidade, quando comparamos as falas com as respostas contidas no questionário que aplicamos no início do processo. Nas sessões seguintes iremos transcrever e analisar as respostas contidas no questionário, como também suas falas anotadas no Diário de
Campo e durante as entrevistas.

Para concluirmos este ponto sobre a pesquisa qualitativa que realizamos, entendemos que para o educando realmente aprender, não devemos quantificar a aprendizagem. Como já afirmava Ausubel (apud DANTAS, 2011), que nos currículos educacionais a abordagem de ensino expositivo e de aprendizagem por recepção, fomenta a aprendizagem de verbalismo vazio, e está fortemente desprovido de significados e de compreensão.

\subsection{O Público e o Local da Pesquisa}

O espaço de investigação escolhido para referida pesquisa foi uma escola pública de educação profissional da rede estadual de ensino, localizada no município de Pereiro - CE. O estudo dirigiu-se a uma turma de $3^{\circ}$ ano do ensino médio do curso de Técnico em Redes de Computadores, com um total de 34 alunos. A escolha por alunos do $3^{\circ}$ ano se deu pelo fato que estes são mais maduros e detentores de mais conhecimentos prévios. Também partimos do princípio que os mesmos teriam maior facilidade de compreensão, visto a abstração dos conteúdos que foram escolhidos para serem trabalhados.

\subsection{Os Instrumentos da Pesquisa}

Neste trabalho utilizamos um questionário no início da intervenção e uma entrevista no final da mesma, e para auxílio nas análises de dados, utilizamos também um Diário de Campo. O questionário contou com perguntas abertas, tendo em vista que esse modo de questionário permite deixar os educandos mais livres para suas respostas. Já a entrevista foi semiestruturada, sendo que: "Uma grande 
vantagem desse instrumental é a interação entre o pesquisador e o entrevistado" (COSTA; COSTA, 2011, p. 49).

Qual o objetivo do questionário nesse estudo de pesquisa? De acordo com Costa e Costa (2011, p. 47): "[...] a grande vantagem do questionário, como instrumento de coleta de dados, é a sua capacidade de atingir um grande número de pessoas $[\ldots]$ ", tendo em vista que trabalhamos com uma turma de 34 alunos. Com os questionários, também tivemos a pretensão de entender e descobrir possíveis caminhos metodológicos que nos levariam as simulações computacionais, pois, o ato de ensinar exige uma reflexão crítica a respeito de nossa prática. Nessa perspectiva argumenta:

Por isso, é fundamental que, na prática da formação docente, o aprendiz de educador assuma que o indispensável pensar certo não é presente dos deuses nem se acha nos guias de professores que iluminados intelectuais escrevem desde o centro do poder, mas, pelo contrário, o pensar certo que supera o ingênuo tem que ser produzido pelo próprio aprendiz em comunhão com o professor formador. (FREIRE, 1996, p. 22)

Mas, o principal objetivo do questionário foi descobrir o conhecimento prévio do educando acerca dos conteúdos trabalhados nas simulações.

Com a entrevista no final do processo, procuramos diagnosticar se o educando conseguiu ter uma aprendizagem realmente significativa, mas também verificar se esta ratificou observações contidas no próprio Diário de Campo. Avaliamos então, de acordo com suas respostas, se o conhecimento foi reformulado após a utilização do PhET, e procuramos relacionar o conhecimento adquirido com o conhecimento prévio. A entrevista foi realizada com oito alu- nos, escolhidos aleatoriamente.

A seguir, todas as atividades do processo de intervenção serão descritas.

\subsection{Momentos da Pesquisa}

Para a intervenção, realizamos quatro encontros, um por semana, sendo todos realizados no mês de março de 2013. Cada encontro teve duração de 100 minutos, composto de duas aulas de 50 minutos. Sendo a entrevista realizada no último encontro.

No primeiro encontro aplicamos o questionário para análise dos conhecimentos prévios dos alunos e apresentamos o Portal PhET. Diante disso, já percebemos um fato curioso entre os alunos; os mesmos ficaram empolgados com a grande quantidade de simulações que estão dispostas no Portal. Realizamos uma exposição oral dos conteúdos em pauta - cargas elétricas e corrente elétrica, e a seguir, na própria sala de aula, utilizamos um computador e um data show para apresentarmos uma simulação sobre cargas elétricas ${ }^{2}$.

Com o objetivo de reforçar o conhecimento dos educandos sobre a importância da energia na sociedade atual, seus benefícios e malefícios, assistimos um documentário - Entendendo a Eletricidade - Discovery Channel ${ }^{3}$, havendo a seguir uma discussão sobre o vídeo. Resolvemos realizar esta atividade antes das simulações, para fazermos relação deste documentário com as simulações e com o conteúdo de física que pretendíamos trabalhar. Alguns questionamentos foram colocados para todos e discutidos em grupo. Destacamos aqui um comentário, em que alunos falaram sobre a

\footnotetext{
2 Disponível em: <http://phet.colorado.edu/en/simulation/ balloons> Acessado em 05 de março de 2013.

3 Disponível para download em: <http://download-ak.com/ discovery-channel-tudo-sobre-eletricidade-dvdrip > Acessado no dia 05 de janeiro de 2012.
} 
imensa contribuição da eletricidade na nossa sociedade: Dependemos diretamente dela, argumentaram.

Utilizamos no segundo encontro, para a abordagem do conteúdo corrente elétrica, um artigo da revista Física na Escola ${ }^{4}$, que tem o tema: A Física da tempestade e dos raios ${ }^{5}$. 0 texto em questão foi utilizado para gerar discussões sobre os raios, e confrontar com os conteúdos a serem trabalhados (corrente elétrica, potencial elétrico e resistência elétrica). Utilizamos neste encontro o laboratório de informática para trabalhamos com o PhET, e realizarmos mais uma simulação, agora sobre corrente elétrica ${ }^{6}$, e tendo os estudantes acesso direto ao Portal.

No terceiro encontro realizamos mais simulações, surgindo assim mais questionamentos, o que provocou uma excelente discussão sobre as simulações apresentadas, como veremos mais a frente. $\mathrm{O}$ quarto encontro foi reservado à entrevista com os alunos, finalizando então o nosso momento de pesquisa em sala de aula.

\section{Análise e Interpretação dos Da- dos}

No primeiro encontro apresentamos aos educandos todo planejamento das atividades que seriam trabalhadas em sala de aula, neste processo de investigação. Enfatizamos que inicialmente iríamos aplicar um questionário com o intuito de descobrir os conhecimentos prévios (possíveis subsunçores de Ausubel), es-

\footnotetext{
${ }^{4}$ Revista Física na Escola. A Física na Escola é um suplemento semestral da Revista Brasileira de Ensino de Física (RBEF) destinada a apoiar as atividades de professores de Física do Ensino Médio e Fundamental. Disponível em: <http://www. sbfisica.org.br/fne/> Acessado em 07 de fevereiro de 2013.

${ }^{5}$ Disponível em: <http://www.sbfisica.org.br/fne/Vol2/Num1/ raios.pdf> Acessado em 07 de fevereiro de 2013.

${ }^{6}$ Disponível em: < http://PheT.colorado.edu/en/simulation/circuit-construction-kit-dc> Acessado em 12 de março de 2013.
}

pecificamente sobre os conteúdos que seriam trabalhados. Conhecendo estes subsunçores, fazendo uso das TIC e aplicando a metodologia descrita acima, tínhamos como objeto levar os estudantes a uma aprendizagem significativa.

Quando o conteúdo escolar a ser aprendido não consegue ligar-se a algo já conhecido, ocorre o que Ausubel chama de aprendizagem mecânica, ou seja, quando as novas informações são aprendidas sem interagir com conceitos relevantes existentes na estrutura cognitiva. Assim, a pessoa decora fórmulas, leis, mas esquece após a avaliação. (PELIZZARI et al., 2002, p. 38)

Sabemos o quanto é difícil para os educandos compreenderem alguns conceitos sobre eletricidade, que na maioria das vezes são abstratos e contrastam com o seu conhecimento prévio, tornando muito difícil fazer com que o mesmo entenda a necessidade de mudar essa concepção. Vejamos, no quadro abaixo, algumas respostas ao questionário.

Quadro 1 - Respostas da Questão Referente ao Entendimento do Conceito de Carga Elétrica

QUESTÃO 01:

De acordo com RODITI (apud SILVA, 2011, p. 99). "A Eletrostática, é o ramo da Física que investiga as propriedades e o comportamento dos campos elétricos de cargas elétricas ou fontes de cargas estacionárias, ou seja, ela se ocupa das propriedades das cargas elétricas em repouso".

Descreva abaixo o que você entende por cargas elétricas.

Algumas respostas:

FE: São todos os materiais que são constituídos de átomos e os átomos são constituídos de pela concepção mais clássica de prótons $(p)$, nêutrons e elétrons (e)

FJ: É uma carga de um elétron. Ou seja, o movimento que os elétrons fazem. 
JN: São pequenas ou grandes quantidades de
energias em um condutor.
FB: Cargas elétricas são partículas de elétrons que
giram e provocam movimento gerando energia.
MF: Carga elétrica pra mim é a quantidade de energia
que passa pelos fios.
LK: Algo que contém energia, que fornece energia.
ED: São os movimentos dos elétrons
SM: É um pouco de energia que se localiza em uma
determinada região

Fonte: Elaborado pelos próprios autores.

Todos os alunos responderam à Questão 01 , no entanto percebemos que alguns tinham conhecimentos prévios alternativos (do senso comum), sobre o conceito de carga elétrica. Os alunos FJ, MF e ED confundem claramente o conceito de carga elétrica com o conceito de corrente elétrica, quando falam sobre movimentos de cargas em um condutor. O aluno FB confunde o simples conceito de carga elétrica com o conceito de gerador elétrico. Já o aluno SM, fala sobre campo elétrico. Assim, percebemos que a grande maioria dos alunos desconhece, ou conhece de forma equivocada, o conceito de carga elétrica.

Com tais respostas, podemos afirmar que estes educandos têm seus conhecimentos prévios sobre este ponto, pois todos opinaram, mas ao mesmo tempo, não podemos denominar tais conhecimentos como subsunçores. Como diz a teoria da Aprendizagem Significativa de Ausubel, que os subsunçores serviriam para que a partir de um conhecimento básico, se chegasse a um conhecimento mais aprofundado do conteúdo. Tivemos assim, que inicialmente expor o conteúdo aos educandos, para somente a seguir aprofundar os conceitos e chegar à aprendizagem significativa. Seguindo com a Questão 02:

Quadro 2 - Respostas da Questão Referente ao Entendimento do Conceito de Corrente Elétrica

\section{QUESTÃO 02:}

Sobre o modelo atômico, segundo Silva (2011, p. 100). Rutherford idealizou um novo modelo atômico; o qual consistia numa região central, chamada de núcleo atômico, que é constituído de prótons e nêutrons, e ao seu redor existia a eletrosfera constituída por elétrons.

Descreva o que você entende por corrente elétrica.

Algumas respostas:

$\mathrm{KL}$ : é uma força que serve para ligar uma televisão

JN: É a passagem dos elétrons livres em um condutor

FJ: É uma corrente de elétrons, o movimento que os elétrons fazem.

AR: É a energia transmitida pelos condutores (fiação)

GS: É a carga resultante que passa em toda a rede elétrica

MQ: É a passagem de carga negativa e positiva

SP: É a corrente que flui em um corpo para o outro quando ele recebe algum tipo de descarga.

Fonte: Elaborado pelos próprios autores.

Percebemos na Questão 02, que a maioria dos alunos tinha um bom conhecimento prévio sobre corrente elétrica, como pode ser visto acima nas repostas dos alunos JN e FJ. Mas, o aluno KL confunde o conceito de corrente elétrica com potencial elétrico. Nesta questão, os alunos ED e GE não responderam, mas observamos que a maioria relaciona corrente elétrica com o movimento das cargas elétricas. Aqui, os alunos tinham os subsunçores necessários para a continuação dos estudos. Vejamos mais uma questão: 
Quadro 3 - Respostas da Questão Referente ao Entendimento do Conceito de Corrente Elétrica

$\begin{aligned} & \text { Que partícula contida no átomo é } \\ & \text { responsável por transmitir a corrente } \\ & \text { elétrica? Como ocorre esse processo? }\end{aligned}$
Algumas respostas:
SP: Os elétrons. Ocorre que passa por todo o material
LK: Elétrons. Eles vão passando um pelo outro e
transmitindo energia por cada coisa que passa.
VM: Os elétrons. Eles e mechem e vão passando
eletricidade um para o outro
ME: Elétron. Vários elétrons juntos vão se movendo
até a energia ser transmitida através da corrente.
JG: Os elétrons. Eles vibram e vai passando as
correntes de um para o outro
FE: Os prótons ( $\mathrm{p}$ ), os nêutrons ( $\mathrm{n}$ ) e os elétrons (e).
Ocorre de forma negativa e positiva.

Fonte: Elaborado pelos próprios autores.

Identificamos que os alunos acima têm uma boa noção sobre corrente elétrica, relacionando-a com o movimento de cargas, mas, quando são questionados sobre como acontece esse processo, estes ainda não têm um bom fundamento científico sobre o tema. Os alunos JD, $\mathrm{ED}, \mathrm{GE}, \mathrm{FW}, \mathrm{FJ}$ e $\mathrm{FB}$ responderam que a partícula responsável pelo processo da corrente é o elétron, no entanto, os mesmos não souberam explicar como isso ocorre.

Em virtude disso percebemos que alguns alunos conheciam corretamente o processo da corrente elétrica, e outros entendiam apenas que a partícula responsável por ela é o elétron, sem justificar como ocorre isso. Continuando, temos a Questão 04:
Quadro 4 - Respostas da Questão Referente ao Entendimento do Conceito de Energia e Potencial Elétrico

QUESTÃO 04:

Para que ocorra o movimento de qualquer objeto, é preciso que seja gasta alguma quantidade de energia. Em relação à corrente elétrica, qual é a relação conceitual entre Energia e Potencial Elétrico?

Algumas respostas

FJ: Energia é a capacidade que um corpo tem de realizar trabalho e potencial elétrico é a potência do trabalho

VM: Energia é o que é passado de um elétron para o outro. Potencial elétrico é com que potência essa energia passa

FB: Energia é o que liga a luz. Potencial é a quantidade de luz que esquenta

Fonte: Elaborado pelos próprios autores.

Esta questão foi formulada com o intuito de analisar o conhecimento prévio dos alunos sobre a relação entre energia e potencial elétrico. Apenas três alunos responderam essa questão (FJ, VM e FB), mas ainda de maneira equivocada. Em virtude disso, percebemos que estes não têm um conhecimento prévio adequado sobre potencial elétrico, e às vezes confundem com potência elétrica, como comenta o aluno FJ: potencial elétrico é a potência do trabalho. E o aluno VM confundiu energia elétrica com corrente elétrica, quando comentou sobre o fluxo de energia entre os elétrons.

Percebemos que o conhecimento prévio dos educandos é mais próximo da explicação científica para determinados conteúdos, e para outros não. Assim, o resultado deste questionário, serviu de orientação para sabermos de fato quais são os conhecimentos prévios que devem ser reforçados e quais conhecimentos devem ser modificados na estrutura cognitiva dos educandos. 


\subsection{Usando o PhET e Construindo as Simulações}

No primeiro encontro, além da aplicação do questionário apresentado acima, o Portal PhET foi utilizado na própria sala de aula, com um notebook e um datashow, quando mostramos uma simulação sobre cargas elétricas. Ainda antes dessa simulação fizemos um experimento simples e prático em sala sobre a eletrização por atrito, usando uma caneta e pedaços pequenos de papel. Explicamos como acontecia o processo de atração entre a caneta e os pedacinhos de papel. Consideramos o experimento feito antes da simulação, importante no contexto pedagógico, pois faz o elo com a simulação que iríamos trabalhar a seguir. Lembrando sempre que não devemos abdicar de experimentos práticos em virtude de simulações. A simulação é usada para auxiliar no entendimento da prática e são usadas principalmente quando os experimentos práticos são complicados de serem realizados, ou têm custo alto.

Simulações computacionais de experimentos de Física têm sido há anos desenvolvidas e utilizadas tanto pelo seu potencial pedagógico quanto para mitigar o problema dos custos e das dificuldades logísticas das atividades experimentais. (SILVA, 2012, p. 4)

Ainda neste primeiro encontro, trabalhamos com o vídeo Entendendo a Eletricidade, provocando mais interatividade entre os alunos e professor.

No segundo e terceiro encontro fomos para - laboratório de informática, onde os alunos se dividiram em duplas para cada computador. Abrimos o Portal PhET e seguimos orientando os alunos para a construção das simulações. Utilizamos também neste segundo encontro o artigo - A Física da Tempestade e dos Raios ${ }^{7}$, fazendo, a seguir, relações com simulações trabalhadas neste encontro. Propomos aos estudantes que utilizassem uma simulação sobre a interação entre cargas elétricas, e quando todos terminaram, dialogamos sobre os conceitos que podiam ser entendidos.

Ao utilizarem uma simulação que continha balões a serem eletrizados, percebemos que alguns alunos escolheram uma opção onde era possível usar dois balões, e assim, descobriram o que acontecia quando os dois estavam eletrizados com a mesma carga, ou com cargas diferentes. Tivemos o comentário: é possível descobrir como funciona a física se todos os professores aplicassem simulações na sala de aula.

Observamos que a utilização do Portal PhET provocou mais interesse e entusiasmo nos alunos. Este se mostrou útil na busca pela aprendizagem significativa, pois é uma ferramenta que instiga a curiosidade e a vontade de aprender dos educandos, fazendo com que eles deem significado aos conteúdos estudados.

A seguir os estudantes utilizaram uma simulação para verificar o processo da corrente elétrica e potencial elétrico. Percebemos uma grande euforia nesse momento, ficando até difícil o direcionamento do trabalho, pois os mesmos estavam verificando, por si só, todas as funções do simulador, e até questionando-as.

$O$ aluno ED quando foi construir um circuito elétrico, por acidente, conectou com um fio condutor as duas extremidades da bateria, e percebeu que o circuito pegou fogo. O aluno gritou: descobri aqui um curto-circuito. Então pedimos que todos também fizessem no seu

\footnotetext{
${ }^{7}$ Este é um artigo de Marcelo Saba, que pode ser encontrado na revista Física na Escola. Esta é uma publicação da Sociedade Brasileira de Físicos (SBF).
} 
computador esse exemplo do curto-circuito. A seguir todos construíram um circuito com duas baterias, uma lâmpada e um interruptor. $\mathrm{O}$ aluno FW estava com dificuldades, e então pedimos para quem terminasse a simulação, ajudasse o mesmo. Fizemos isso com o objetivo de proporcionar a aprendizagem do aluno utilizando o conhecimento do outro.

Quando todos concluíram, analisamos o fluxo dos elétrons no condutor, para em seguida aumentarmos o número de baterias. Então questionamos o que acontecia com a corrente elétrica: todos falaram que aumentava, pois a velocidade dos elétrons aumentava. Pedimos que utilizassem os instrumentos disponíveis no simulador, como voltímetro e amperímetro para medir a tensão e a corrente do circuito, quando se variava o número de baterias e resistências elétricas.

Durante esse processo da investigação percebemos que o uso de simulações estimulou a aprendizagem por descoberta, fazendo com que os alunos apresentassem soluções para os problemas propostos.

\subsection{Analisando a Aprendizagem de Acordo com as Falas dos Alunos Du- rante a Entrevista}

A entrevista é uma parte do processo investigativo muito importante, pois nela analisamos as falas dos alunos de acordo com a intervenção realizada. Esta atividade foi desenvolvida no quarto encontro, com oito estudantes.

Inicialmente lançamos uma pergunta sobre a opinião dos alunos sobre a importância do uso de simuladores em sala de aula. Destacamos a opinião da aluna BN: É porque a gente é, só escrever né? Uma aula é cansativa, aí quando você vê na prática é bem mais melhor, e só falando não dá pra entender. Que nem
(" $L R$ " professora do eixo técnico) explicava mais a gente não entendia como funcionava de verdade, ali a gente entende.

Percebemos nessa fala, que a aluna comenta uma vantagem acerca de observar, na prática, o que diz a teoria, mesmo sendo uma simulação computacional. Com esse mesmo questionamento o aluno AR comenta: Eu entendo mais, chama mais a atenção, tem coisas que só falando não dá pra entender.

Perguntamos aos alunos sobre a frequência do uso das simulações em sala de aula. Constatamos, pelos relatos dos alunos, que raramente são usados. Os alunos VM, LK, AR e JG comentaram que não lembravam se os professores tinham usado simulações em sala de aula.

Questionamos sobre a utilização do Portal PhET durante as aulas. O objetivo aqui foi constatar se os alunos tiveram dificuldades ou não em utilizar o Portal, e também para destacarmos possíveis pontos positivos ou negativos. A aluna BN fez o seguinte comentário: eu achei simples, porque a gente já conhecia algumas coisas, como interruptor, bateria.

Neste ponto conseguimos confrontar a fala da aluna com a teoria da Aprendizagem Significativa de Ausubel. A aluna já tinha os conceitos de interruptor e bateria ancorados na sua estrutura cognitiva, e com a visualização das simulações aplicadas, a mesma reformulou esse conhecimento e internalizou o novo conhecimento adquirido. Ainda nesta parte, destacamos a fala do aluno AR, onde o mesmo fala: as opções com aqueles desenhos ficam mais fácil de entender, escolher, às vezes mesmo sem nomes você já sabe o que fazer.

A aluna BN relacionou uma simulação com o seu cotidiano, quando argumenta: na hora que a gente monta você levanta o interruptor (risos) aí vê se tá certo ou se tá errado, pode 
queimar (risos), o de (ED aluno da turma) queimou, se você fizer a fiação de uma casa, se você fizer errado como a gente tava fazendo no computador pega fogo na sua casa. A gente pelo formato já via o desenho do resistor, da bateria e tudo mais, só que os elétrons se você fosse montar na fiação você num ia vê ele transcorrendo né?

Percebemos que a aluna revela a experiência da simulação como uma possibilidade de ver os elétrons se movimentando, algo que não é visto diretamente nem em um ótimo laboratório com experimentos reais.

Questionamos diretamente sobre o objetivo das simulações: os balões carregados e o circuito simples, (citadas anteriormente). Destacamos a fala do aluno AR: na montagem dos circuitos o objetivo foi que é, a gente vê assim, a gente num consegue vê aqueles elétrons passando assim, entendeu assim? Olhando, só olhando, a gente num consegue vê, se a gente fizer na prática e naquilo ali a gente consegue vê como é que eles passam. Aqui, o aluno reforça a ideia de ver o movimento dos elétrons.

Percebemos que quando o aluno falava do conhecimento que possuía e associava com o novo, ficava mais fácil compreender o fenômeno físico, como comenta a aluna BN: é e a gente já usou os conhecimentos que a gente já tinha anteriormente e se aprofundou ainda mais.

Constatamos na aplicação do questionário prévio, que os alunos confundiam os conceitos de corrente elétrica, resistência elétrica e potencial elétrico. Assim, durante a entrevista pedimos que os mesmos fizessem comentários sobre esses conteúdos, de acordo com as simulações feitas como Portal PhET. Destacamos a fala do aluno $A R$, que comentou: quando a resistência do circuito aumenta a corrente diminui, porque a resistência faz com que ele, como é que se diz? Faz uma pequena barreira e eles vão passando, mas que não passam na mesma velocidade. Percebemos aí que o aluno compreendeu a relação entre corrente elétrica e resistência elétrica.

Questionamos também a relação entre a corrente elétrica e o potencial elétrico. Vejamos o comentário da aluna BN: dava até pra ver quando (ED aluno da turma) ele estava montando diferente do que você estava ensinando né, aí uma parte ele colocou mais resistores aqui aí ficou só um pouquinho os elétrons mexendo bem devagarzinho, do outro lado ele colocou um monte de bateria e ficou mais rápido.

Um objetivo dessa investigação foi analisar a aprendizagem dos alunos usando o Portal PhET, comparando esta aprendizagem com o conhecimento prévio dos mesmos. Baseado nisso, vejamos o comentário do aluno AF: Muito mais, com certeza, porque ó, geralmente se tivesse sempre só falando a gente ia entender um pouco mais no momento depois a gente ia complicar e quando a gente para pra fazer, montar é, no simulador a gente já adquire aquele conhecimento só pra gente entendeu? Exemplo, quando eu monto um circuito eu sei, naquela hora que tava passando a corrente a gente só ia imaginar não ia vê como era que passava.

Sobre a facilidade de compreensão de conteúdo de eletricidade usando o PhET o aluno AR comenta: quando é na teoria você só sabe, mas os termos as vezes você troca um ou outro e quando você vê abaixo o que cada um faz você já não troca mais, chamar um resistor de capacitor, essas coisas assim.

Os alunos aprovaram o uso de simulações em sala de aula, comentando sobre a sua importância no processo de ensino-aprendizagem na disciplina de Física, e que o PhET é utilizado 
para mostrar fenômenos que às vezes, só com o uso da teoria, é mais complicado para o professor transmitir e para os alunos entenderem.

\section{Considerações Finais}

De acordo com o principal objetivo do nosso trabalho, onde pretendíamos mostrar a importância do uso de simulações no ensino de física, percebemos que podemos usar os recursos do Portal PhET como uma ótima ferramenta didática, pois observamos que durante todo o processo de intervenção, os alunos ficaram curiosos com esse tipo de recurso, o que os levou a uma evolução da aprendizagem dos conteúdos estudados. Mas ainda devemos medir, pesquisar, se seu uso do Portal PhTE pode ser feito de forma generalizada para o ensino de ciências.

Ao analisarmos os dados da investigação percebemos que alguns educandos possuíam conhecimentos prévios para alguns conceitos físicos, onde uns podiam ser denominados como subsunçores e outros não. O uso das simulações ajudou os educandos a questionarem esses conhecimentos, reestruturando-os, formando assim um conhecimento mais aprofundado sobre os conceitos científicos.

Os alunos perceberam que as aulas somente expostas oralmente pelos professores são cansativas, e comentaram que trabalhando com as simulações, sentiam-se mais motivados em aprender. Destacamos a fala do aluno AR: Eu entendo mais, chama mais a atenção, tem coisas que só falando não dá pra entender.

Um ponto importante das análises da nossa pesquisa foi os alunos comentarem que o Portal PhTE é muito simples de usar, e que algumas coisas apresentadas nele, os mesmos já conheciam. Durante os encontros da pesquisa e com a entrevista no final do processo, com- provamos uma maior aprendizagem dos alunos, e que os mesmos tiveram mais prazer em aprender, pois se sentiam descobrindo as leis físicas.

Constatamos que o uso das simulações contribuiu para a melhoria do aprendizado dos alunos do conteúdo de física proposto. Segundo o aluno AF: geralmente quando o professor só fala o aluno até entende, mais logo esquece, e quando isso é feito na prática, mesmo de forma virtual, quando eles mesmos montam as simulações, os mesmos aprendem o conteúdo. Daí então, entendemos que as simulações apresentadas pelo Portal PhET, se configuraram numa ferramenta importante para auxiliar o aprendizado dos educandos. As simulações ajudaram os alunos na assimilação do conhecimento e a melhorar sua aprendizagem para os conceitos básicos de eletricidade, pois durante todo o trabalho de investigação o aprendizado foi ressaltado pelos próprios alunos.

Durante todo o processo da pesquisa tentamos associar o uso das simulações com a teoria da Aprendizagem Significativa de Ausubel. Percebemos que quando o aluno já tem um conhecimento prévio em seu cognitivo, seja ele um subsunçor ou não, e esse conhecimento é confrontado com o novo, usando a tecnologia, obtemos um resultado satisfatório, levando o educando a uma aprendizagem significativa.

Finalmente, concluímos que o uso das TIC, em particular do Portal PhET, influenciou satisfatoriamente os educandos a um melhor aprendizado sobre os conteúdos de eletricidade propostos neste trabalho. Acreditamos que o uso deste Portal pode ajudar de forma significativa para a melhor percepção dos demais conteúdos de física, além de aumentar o interesse e motivação dos alunos. Constatamos também, que as simulações computacionais fazem com que o professor não seja mais o 
detentor do conhecimento e sim um mediador, em um mundo onde com as tecnologias, se bem utilizadas, podem contribuir significativamente no aprender e no ensinar.

\section{Agradecimentos}

Ao professor Claudio Rejane da Silva Dantas pelas importantes sugestões e discussões durante a execução deste trabalho, e ao De- partamento de Física da Universidade Regional do Cariri, pelas condições oferecidas.

\section{Referências}

ARANTES, Alessandra Riposati; MIRANDA, Márcio Santos; STUDART, Nelson. Objetos de Aprendizagem no Ensino de Física: usando simulações do PhET. A Física na Escola, São Paulo, v. 11, n. 1, p. 27-31, 2010.

ASMANN, Hugo (Org.). Redes Digitais e Metamorfoses do Aprender. Petrópolis, RJ: Vozes, 2005.

AUSUBEL, David Paul. Aquisição e Retenção de Conhecimento: uma perspectiva cognitiva. Lisboa: Plátano, 2002.

BOGDAN, Roberto; BIKLEN, Sari Knopp. Investigação Qualitativa em Educação. Lisboa: Porto Ed., 1994.

BRANDÃO, Zaia. Pesquisa em Educação: conversas com pós-graduandos. Rio de Janeiro: Ed. PUCRio; São Paulo: Loyola, 2002.

COSTA, Marco Antônio F. da; COSTA, Maria de Fátima Barrozoda. Projeto de Pesquisa: entenda de faça. 2. ed. Petrópolis, RJ: Vozes, 2011.

DANTAS, Claudio Rejane da Silva. As Tic's e a Teoria da Aprendizagem Significativa: uma proposta de intervenção no ensino de Física. Dissertação (Mestrado) - Programa de Pós-graduação em Ensino de Ciências e Matemática, Universidade Estadual da Paraíba, 2011, Campina Grande, BR-PB. 
DANTAS, Claudio Rejane da Silva; MOITA, Filomena; GERMANO, Marcelo Gomes. Ensinar e Aprender Física com Apoio de Recursos Digitais: enfoque na Aprendizagem Significativa. Informática na Educação: teoria \& prática, Porto Alegre, v. 17, n. 1, p. 145-153, jan./jun. 2014.

FREIRE, Paulo Reglus Neves. Pedagogia da Autonomia: saberes necessários a prática educativa. São Paulo: Paz e Terra, 1996. (Coleção Leitura)

JONASSEN, David. O Uso das Novas Tecnologias na Educação a Distância e a Aprendizagem Construtivista. Em Aberto, Brasília, ano 16, n. 70, p. 70-88, abr./jun.1996.

KENSKI. Vani Moreira. Novas Tecnologias: o redimensionamento do espaço e do tempo e os impactos no trabalho docente. Revista Brasileira de Educação, Belo Horizonte, n. 8, p. 58-71, maio/ago. 1998.

LOPES, José Junio. A Introdução da Informática no Ambiente Escolar. [S.I.: s.n.], 2004. Artigo enviado ao Clube do professor em 23 de fevereiro de 2004. Disponível em: <http://www.clubedoprofessor.com.br/artigos/artigojunio.pdf> Acesso em: 11 ago. 2013.

MELO, Ruth Brito de Figueiredo. A Utilização das TIC'S no Processo de Ensino e Aprendizagem da Física. In: SIMPÓSIO HIPERTEXTO E TECNOLOGIAS NA EDUCAÇÃO: REDES SOCIAIS E APRENDIZAGENS, 3., Recife, 2010. Anais Eletrônicos. [Recife]: UFP, 2010. P. 1-12. Disponível em: <http://www. nehte.com.br/simposio/anais/Anais-Hipertexto-2010/Ruth-Brito-de-Figueiredo-Melo.pdf> Acesso em: 11 ago. 2013.

MORAN, José Manuel. O Vídeo na Sala de Aula. Comunicação e Educação, São Paulo, n. 2, p. 27-35, jan./abr. 1995.

NEVES, José Luís. Pesquisa Qualitativa: características, usos e possibilidades. Caderno de Pesquisas em Administração, São Paulo, v. 1, n. 3, p. 1-5, 2. sem. 1996.

NOBRE, Francisco Augusto Silva; DANTAS, Cláudio Rejane da Silva; ANDRADE JUNIOR, José Adauto. O Estudo de Energia: uma experiência de ensino na perspectiva CTS e o uso de mídias. Experiências em Ensino de Ciências, Cuiabá, v. 5, n. 1, p. 21-29, 2010.

PELIZZARI, Adriana et al. Teoria da Aprendizagem Significativa Segundo Ausubel. Revista Psicologia Educação Cultura, Vila Nova de Gaia, v. 2, n. 1, p. 37-42, jul. 2001/jul. 2002.

POCINHO, Ricardo Filipe da Silva; GASPAR, João Pedro Marceneiro. O Uso das TIC e as Alterações no Espaço Educativo. Exedra, Coimbra, n. 6, p. 143-154, 2012.

PORTAL PheT. Disponível em:<http://PheT.colorado.edu/en/simulations/category/new> 
Vídeo: Entendendo a eletricidade - Discovery Channel. Disponível em: <http://download-ak.com/ discovery-channel-tudo-sobre-eletricidade-dvdrip>

SABA, Marcelo M.F. A Física das Tempestades e dos Raios. Física na Escola, v. 2, n. 1, 2001

SANTOS, Rogério Santana dos. Cresce o Acesso às TICs, mas Ainda é Grande o Desafio de Democratizá-las a Todos os Brasileiros. In: CGI.br (Comitê Gestor da Internet no Brasil). Pesquisa Sobre o Uso das Tecnologias da Informação e da Comunicação 2008. São Paulo, 2009. P. 45-48.

SILVA, Claudio Xavier; BARRETO FILHO, Benigno. Coleção Física Aula por Aula. São Paulo: FTD, 2010. V. 3.

SILVA, Maria Aldia da; MOITA, Filomena. Práticas Educativas no Ensino de Física e as Interfaces Digitais. [S.I.: s.n.]. Disponível em: <http://bocc.ubi.pt/pag/silva-moita-praticas-educativas-no-ensino-de-fisica-e-as-interfaces-digitais.pdf> Acesso em: 10 jan. 2013.

SOUZA, Antonio Marcos de; NAZARÉ, Tiago Santana. A utilização de um programa de computador para simulações de experimentos de óptica como forma de promover o aprendizado das ciências exatas. Revista Física na Escola, v. 13, n. 1, 2012.

SILVA, José Nilson. Uma abordagem histórica e experimental da Eletrostática. Disponível em: http://periodicos.unifap.br/index.php/estacao/article/view/126/v1n1Jose.pdf. v. 1, n. 1, p. 99-113, 2011. Acesso em: 9 jun. 2013.

Submetido para avaliação em 21 de novembro de 2014

Aprovado para publicação em 08 de outubro de 2015.

Francisco Vanderli de Araújo - Universidade Regional do Cariri, Crato, BR-CE. E-mail: vanderlifisica@gmail.com Francisco Augusto Silva Nobre - Universidade Regional do Cariri, Crato, BR-CE. E-mail: augusto.nobre@urca.br José Adauto Andrade Junior - Universidade Regional do Cariri, Crato, BR-CE. E-mail: adautoandrade@hotmail.com Claudio Rejane da Silva Dantas - Universidade Regional do Cariri, Crato, BR-CE. E-mail: claudiodantas25@yahoo. com.br 